\title{
Pengaruh Efektivitas Penerapan Absensi Finger Print Terhadap Disiplin Pegawai Negeri Sipil di Sekretariat Daerah Kabupaten Raja Ampat Papua Barat
}

\author{
${ }^{1}$ Evi Mufrihah Zain, ${ }^{2}$ Febry Jein Andjar, ${ }^{3}$ Rais Dera Pua Rawi, \\ ${ }^{4}$ Fridolin F Fakdawer \\ Universitas Muhammadiyah Sorong, Kota Sorong, Indonesia \\ Email : ${ }^{3}$ raisderaprawi@um-sorong.ac.id
}

(Diterima: Oktober 2021; Direvisi: Oktober 2021; Dipublikasikan: Januari 2022)

\begin{abstract}
ABSTRAK
Absensi Fingerprint merupakan Alat yang digunakan untuk melihat kehadiran pegawai secara komputerisasi. Tujuan penelitian ini yaitu menguji pengaruh Efektivitas Penerapan Absensi Fingerprint Terhadap Disiplin Pegawai Negeri Sipil Di Sekretariat Daerah Kabupaten Raja Ampat Papua Barat. Populasi dalam penelitian ini adalah seluruh karyawan di Sekretariat Daerah Kabupaten Raja Ampat yaitu 35 orang dikarenakan jumlah populasi yang kecil maka penelitian ini menggunakan sampel jenuh. Teknik pengumpulan data menggunakan kuesioner. Tahap akhir dari penelitian ini yaitu analisis data dengan menggunakan koefisien Korelasi dan Regresi linier Sederhana.Dari Hasil Penelitian dapat diketahui bahwa berdasarkan pengujian terhadap 35 responden yang tercatat sebagai pegawai negeri sipil di sekretaris daerah Kabupaten Raja Amapat terbukti menerima Ha bahwa “ terdapat pengaruh yang signifikan antara absensi sidik jari (finger print) dengan kedisiplinan pegawai", dan menolak $\mathrm{H}_{0}$ bahwa " tidak terdapat pengaruh yang signifikan antara absensi sidik jari (finger print) dengan kedisiplinan pegawai.
\end{abstract}

\section{Kata Kunci: Absensi Fingerprint, Kedisiplinan Pegawai, Setda Kabupaten Raja Ampat}




\section{PENDAHULUAN}

Kedisiplinan adalah kesadaran dan kesedian seseorang untuk mentaati semua peraturan-peraturan perusahaan dan norma-norma sosial. Afandi (2016), menjelaskan bahwa disiplin kerja adalah suatu alat yang digunakan para manajer untuk mengubah suatu perilaku serta sebagai suatu upaya untuk meningkatkan kesadaran dan kesediaan seseorang mentaati semua peraturan perusahaan dan normanorma social yang berlaku. Absensi merupakan salah satu cara yang diberlakukan Lembaga/ Instansi dalam mengukur kedisiplinan pegawainya.

Berbagai Jenis Absensi yang di berlakukan pada suatu instansi/ Lembaga baik itu secara manual maupun dengan cara menggunakan teknologi yang telah dikembangkan, diantaranya yaitu dengan Absensi Finger Print. Penggunaan teknologi untuk instansi sebagai acuan efektivitas kinerja adalah adanya pengadaan sistem komputerisasi dalam aktivitas kerja salah satunya adalah sistem absensi pegawai menggunakan sistem komputerisasi yang baik yaitu Sistem Biometriks dengan sistem ini pegawai akan lebih cepat karena tidak harus antri terlalu lama dan membuang waktu dan kertas. Instansi bisa menghemat waktu dan uang ketika system komputerisasi yang dijalankan menggunakan biometrics karena tidak perlu ada kartu atau kertas guna mendukung sistem absensi sehingga bagian sumber daya manusia atau penggajian hanya perlu melihat laporan hasil absensi tanpa harus memantau system absensi pegawai.
Ketentuan pelaksanaan absensi melalui mesin sidik jari (finger print) baru dilakukan untuk Asisten Sekretaris Daerah Kabupaten Raja Ampat, Staf Ahli Bupati Raja Ampat, Sekretaris DPRD Kabupaten Raja Ampat, BAPPEDA Kabupaten Raja Ampat, Badan Kepegawaian Daerah Kabupaten Raja Ampat, Satuan Polisi Pamong Praja Kabupaten Raja Ampat, KPPT Kabupaten Raja Ampat, Kantor Perpustakaan dan Arsip Daerah Kabupaten Raja Ampat, Kantor Pemilihan Umum Daerah Kabupaten Raja Ampat, dan bagianbagian di lingkuan Sekretariat Daerah Kabupaten Raja Ampat. Namun, pada akhir tahun 2011 semua Instansi Pemerintah di Kabupaten Raja Ampat sudah menggunaka absensi melalui mesin sidik jari (finger print) dan hasilnya di output ke komputer.

Dari penelitian ini penulis menemukan kenyataan dilapangan bahwa absensi dengan komputerisasi ini tidak memberikan efek yang baik bagi kedisiplinan pada kantor Sekretariat Daerah Kabupaten Raja Ampat Papua Barat hal ini dapat dilihat dari beberapa pegawai. Meskipun diterapkan Absensi Finger print namun kesadaran pegawai di Sekertaris Daerah Kabupaten Raja Ampat masih kurang hal ini dapat dilihat dari perilaku pegawai yang tidak disiplin yaitu sering menunda pekerjaan dan meninggalkan kantor saat jam kerja untuk mengurusi kepentingan pribadi dan terkadang pegawai tidak ijin terlebih dahulu kepada atasan. Sehingga, bila pegawai lain atau atasan membutuhkan pegawai tersebut, akan sulit mencarinya dan pekerjaan kantor menjadi tertunda. 
Dari permasalah tersebut penulis ingin mengetahui; pengaruh penerapan absensi Finger Print terhadap disiplin pegawai Negeri sipil di Sekertaris Daerah Kabupaten Raja Ampat; dan Faktor penghambat penerapan absensi finger print terhadap disiplin Pegawai Negeri Sipil di Sekretariat Daerah Kabupaten Raja Ampat.

\section{TINJAUAN PUSTAKA}

\section{Disiplin Pegawai}

\begin{tabular}{lrr}
\multicolumn{2}{c}{ Kedisiplinan } & merupakan \\
sebuah & kebutuhan & sekaligus \\
tuntutan & dalam & berbagai
\end{tabular}

kehidupan social kemasyarakatan, khususnya pada masyarakat modern di setiap tempat dan waktu, baik diinstitusi pendidikan, instansi pemerintah atau swasta, dan lain-lain. Pegawai adalah orang yang bekerja pada instansi atau perusahaan dan sebagainya. Kepegawaian adalah sifat-sifat mengenai pegawai yakni segala sesuatu yang mengenai pegawai. Sumber daya manusia yang disebut disini salah satunya adalah Pegawai di instansi. Menurut Hasibuan dalam Amalia \& Adman (2017) menyatakan bahwa Disiplin kerja atau kedisiplinan merupakan kesadaran dan kesediaan seseorang mentaati semua peraturan-peraturan perusahaan dan norma-norma sosial.

Menurut Fathoni (2014) indikator disiplin pegawai yaitu:

a. Tujuan dan kemampuan

Tujuan yang akan dicapai harus jelas dan ditetapkan secara ideal serta cukup untuk menantang bagi kemampuan karyawan. b. Teladan Pimpinan

Pimpinan menjadi Teladan dan panutan oleh Bawahannya.

c. Balas Jasa

Balas Jasa (Gaji dan Kesejahteraan) akan memberikan kepuasan dan kecintaan karyawan terhadap perusahaan/ pekerjaanya.

d. Keadilan

Keadilan ikut mendorong terwujudnya kedisiplinan karyawan, karena ego dan sifat manusia yang selalu merasa dirinya penting dan meminta di perlakukan sama dengan manusia yang lainnya.

e. Waskat

Merupakan tindakan nyata dan paling efektif dalam mewujudkan disiplin pegawai dengan waskat ini. Waskat adalah tindakan nyata dan efektif untuk mencegah atau mengetahui kesalahan, memperbaiki kesalahan, memelihara kedisiplinan, meningkatkan prestasi kerja, mengaktifkan peranan atasan dan bawahan, menggali systemsistem kerja yang paling efektif dan menciptakan system internal control yang terbaik dalam mendukung terwujudnya tujuan perusahaan, karyawan dan masyarakat.

f. Sanksi

Sanksi yang semakin berat terhadap karyawan akan semakin takut melanggar peraturan-peraturan perusahaan, sikap dan perilaku indisipliner karyawan akan berkurang. 
g. Ketegasan

Ketegasan pimpinan menegur dan menghukum setiap karyawan yang indisipliner akan mewujudkan kedisiplinan yang baik pada perusahaan tersebut.

h. Hubungan Kemampuan

Hubungan Kemanuasiaan yang harmonis diantara sesama karyawan ikut menciptakan kedisiplinan yang baik pada suatu perusahaan.

\section{Absensi Fingerprint}

Absensi merupakan suatu pendataan kehadiran, bagian dari pelaporan aktifitas suatu institusi, atau komponen institusi itu sendiri yang berisi data kehadiran yang disusun dan diatur sedemikian rupa sehingga mudah untuk dicari dan di pergunakan oleh pihak yang berkepentingan.

Menurut Nugroho (2009) Finger print adalah teknologi yang menunjang untuk keperluan absensi, yang didalamnya mencakup pemasukan, penyimpanan data jam masuk dan jam pulang, serta memproses data tersebut menjadi sebuah laporan yang nantinya dapat digunakan untuk kebijakan-kebijakan yang dilakukan oleh pimpinan.

\section{Efektifitas Penerapan Absensi Finger Print}

Efektifitas menekankan pada hasil yang dicapai, sedangkan efisiensi lebih melihat pada bagaimana cara mencapai hasil yang dicapai itu dengan membandingkan antara input dan output. Menurut Miler dalam Asmira (2016) menjelaskan bahwa arti efektivitas dan efisien yaitu "Efektivitas dimaksudkan sebagai tingkat seberapa jauh suatu system social mencapai tujuannya. Efektivitas pada dasarnya menunjukkan pada taraf tercapainya hasil, sering atau senantiasa dikaitkan dengan pengertian efisien, meskipun sebenarnya ada perbedaan diantara keduanya.

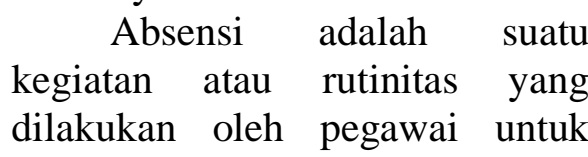
membuktikan dirinya hadir atau tidak hadir dalam bekerja disuatu instansi. Setiawan \& Yulianti (2018), menyatakan bahwa fingerprint adalah teknologi yang menunjang untuk keperluan absensi, yang di dalamnya mencangkup pemasukan, penyimpanan data jam masuk dan jam pulang, serta memproses data tersebut menjadi sebuah laporan yang nantinya dapat dipergunakan untuk pengambilan kebijakankebijakan yang dilakukan oleh pimpinan. Alat ini dilengkapi dengan software untuk melakukan perekaman atas transaksi yang terjadi.

Penelitian empiris tentang Efektivitas Penerapan Absensi Finger Print sudah banyak dilakukan oleh peneliti sebelumnya dengan hasil yang berbeda, penelitian yang dilakukan oleh Rahayu Rahmawati \& Purwadhi (2020) yang menyatakan bahwa ada efektivitas penerapan absensi fingerprint secara parsial berpengaruh positif tidak signifikan terhadap disiplin. Pada penelitiannya Oktafiana et al., (2020) menyatakan bahwa Hasil penelitan menunjukan bahwa penerapan absensi fingerprint 
sebesar $\quad 59.83 \% \quad$ dapat dikategorikan kurang efektif (pada skala 41 - 60). Sehingga untuk meningkatkan efektifitas penerapan absensi fingerprint dapat dilakukan dengan menerapkan peraturan kepegawaian yang lebih ketat dan pemberian peringatan sampai pemotongan gaji kepada pegawai yang tidak patuh pada aturan kepegawaian yang berlaku.

Demikian Pula penelitian yang dilakukan Zulfikar \& Kurniawati, (2020) yang hasilnya menyatakan bahwa pengaruh efektivitas absensi finger print terhadap disiplin pegawai sebesar 0,363 berada pada interval dengan tingkat pengaruh yang rendah.

\section{METODE PENELITIAN}

Penelitan ini bertujuan untuk mengetahi pengaruh Efektivitas penerapan Absensi Finger Print terhadap disiplin kerja pegawai dengan menggunakan pendekatan Kuantitatif dan dilakukan dalam waktu 1 Bulan di kantor Sekretariat Daerah Kabupaten Raja Ampat.

Populasi dalam penelitian ini adalah seluruh karyawan di Sekretariat Daerah Kabupaten Raja Ampat yaitu 35 orang, dikarenakan jumlah populasi yang kecil maka penelitian ini menggunakan sampel jenuh yakni dengan mengambil seluruh populasi yaitu 35 pegawai Sekretariat Daerah Kabupaten Raja Ampat. Teknik pengumpulan data menggunakan kuesioner dan Observasi hasilnya didapatkan data Primer berupa hasil skor kuesioner dari responden secara langsung dan juga data skunder berupa data absen pegawai. Tahap akhir dari penelitian ini yaitu analisis data dengan menggunakan koefisien Korelasi dan Regresi linier Sederhana.

Dibawah ini merupakan diagram model penelitian yang menggambarkan variabel dan hipotesis yang digunakan.

Absensi Finger Print $\rightarrow$ Disiplin Pegawai

\section{Hipotesis Penelitian}

Hipotesis pada penelitian ini adalah:

$$
\begin{aligned}
\mathrm{H}_{\mathrm{a}}= & \text { Terdapat pengaruh yang } \\
& \text { singnifikan antara efektivitas } \\
& \text { penerapan absensi finger print } \\
& \text { terhadap disiplin Pegawai Negeri } \\
& \text { Sipil di Kabupaten Raja Ampat. } \\
\mathrm{H}_{0}= & \text { Tidak Terdapat pengaruh yang } \\
& \text { singnifikan antara efektivitas } \\
& \text { penerapan efektifitas penerapan } \\
& \text { absensi finger print terhadap } \\
& \text { disiplin Pegawai Negeri Sipil } \\
& \text { Kabupaten Raja Ampat. }
\end{aligned}
$$

\section{Pretest}

Untuk mengetahui $r$ hitung peneliti menggunakan alat bantu SPSS for Windows versi 16.0 sedangkan untuk mencari $r$ tabel adalah dengan mencarinya dalam tabel (terlampir) dengan harus mengetahui terlebih dahulu nilai derajat kebebasannya. Derajat kebebasan (degree of freedom) dalam penelitian ini adalah $\mathrm{df}=\mathrm{n}-\mathrm{k}-1$. Dengan ketentuan $\mathrm{n}$ (jumlah responden) adalah 35 responden dan $\mathrm{k}$ (variabel independen) adalah 2 (efektivitas penerapan absensi sidik jari) sehingga besarnya df adalah $35-$ $2-1=32$ dengan alpha $0.05(a=5 \%)$, didapat $r$ tabel 0,349.

Adapun tabel1. Uji Validitas adalah sebagai berikut:

Tabel 1. Hasil Uji Validitas 
JENIUS

\begin{tabular}{|c|c|c|c|c|}
\hline \multirow{3}{*}{ Variabel } & Item & $\begin{array}{c}\text { Corrected } \\
\text { Pertanyaan } \\
\text { total } \\
\text { correlation }\end{array}$ & r table & Keterangan \\
\hline \multirow{4}{*}{ Absensi Sidik Jari (X) } & Q1 & 0,650 & 0.349 & Valid \\
\cline { 2 - 5 } & Q2 & 0,725 & 0.349 & Valid \\
\cline { 2 - 5 } & $\mathrm{Q} 3$ & 0,631 & 0.349 & Valid \\
\cline { 2 - 5 } & $\mathrm{Q} 4$ & 0,667 & 0.349 & Valid \\
\hline \multirow{3}{*}{ Kedisiplinan } & $\mathrm{Q} 5$ & 0,559 & 0.349 & Valid \\
\cline { 2 - 5 } Karyawan (Y) & $\mathrm{Q} 6$ & 0,748 & 0.349 & Valid \\
\cline { 2 - 5 } & $\mathrm{Q} 7$ & 0,552 & 0.349 & Valid \\
\cline { 2 - 5 } & $\mathrm{Q} 8$ & 0,734 & 0.349 & Valid \\
\cline { 2 - 5 } & $\mathrm{Q} 9$ & 0,746 & 0.349 & Valid \\
\hline
\end{tabular}

Sumber: Output spss yang diolah,2018

Sedangakan Hasil pengujian uji reliabilitas instrumen menggunakan alat bantu olah statistik SPSS versi

16.0 for windows dapat diketahui sebagaimana dalam Tabel 2 berikut:

Tabel 2: Hasil Uji Reliabilitas Instrument

\begin{tabular}{|c|c|c|c|}
\hline Variabel & Reliability Coefficient & Alpha & Keterangan \\
\hline $\mathrm{X}$ & 5 item & 0,641 & Reliabel \\
\hline $\mathrm{Y}$ & 5 item & 0,718 & Reliabel \\
\hline
\end{tabular}

Sumber data: Output SPSS, 2018

Dari tabel 2 diatas dapat diketahui bahwa masing-masing variabel memiliki Croncbach Alpha lebih dari 0,60 , yang artinya bahwa semua variabel adalah reliable.

\section{HASIL PENELITIAN}

\section{Analisis Responden}

Dari sebaran kuesioner yang telah dilakukan, berikut adalah analisis data responden dengan berdasarkan karakteristik Jenis kelamin, Usia Responden, Pendidikan dan juga golongan adalah sebagai berikut:

Dekripsi responden berdasarkan jenis kelamin dapat diketahui sebagaimana dalam tabel 3 berikut:

Tabel 3: Jenis Kelamin Responden

\begin{tabular}{|c|c|c|c|c|c|}
\hline \multicolumn{2}{|c|}{} & Freq & Percent & $\begin{array}{c}\text { Valid } \\
\text { Percent }\end{array}$ & $\begin{array}{c}\text { Cumulative } \\
\text { Percent }\end{array}$ \\
\hline \multirow{3}{*}{$\begin{array}{c}\text { Valid } \\
\text { Laki-Laki }\end{array}$} & 24 & 68.6 & 68.6 & 68.6 \\
\cline { 3 - 6 } & $\begin{array}{c}\text { Perempuan } \\
\text { Total }\end{array}$ & 11 & 31.4 & 31.4 & 100.0 \\
\cline { 3 - 6 } & & 100.0 & 100.0 & \\
\hline
\end{tabular}

Sumber: Data Primer yang diolah, 2018.

Tabel 4: Usia Responden

\begin{tabular}{|c|c|c|c|c|}
\hline & Frec & Percent & \begin{tabular}{|l|} 
Valid \\
Percent
\end{tabular} & $\begin{array}{c}\text { Cumulative } \\
\text { Percent }\end{array}$ \\
\hline $\begin{array}{c}20 \text { th s/d } 30 \\
\text { th }\end{array}$ & 1 & 2.9 & 2.9 & 2.9 \\
\hline $\begin{array}{c}31 \text { th } \mathrm{s} / \mathrm{d} 40 \\
\text { th }\end{array}$ & 7 & 20.0 & 20.0 & 20.0 \\
\hline$>40$ th & 27 & 77.1 & 77.1 & 100.0 \\
\hline Total & 35 & 100.0 & 100.0 & \\
\hline
\end{tabular}

Sumber: Data Primer yang diolah, 2018

Tabel 5: Tingkat Pendidikan

\begin{tabular}{|c|c|c|c|c|c|}
\hline \multicolumn{2}{|l|}{} & Freq & Percent & $\begin{array}{c}\text { Valid } \\
\text { Percent }\end{array}$ & $\begin{array}{c}\text { Cumulative } \\
\text { Percent }\end{array}$ \\
\hline Valid & SD & 1 & 2.9 & 2.9 & 2.9 \\
\hline & SMP & 1 & 2.9 & 2.9 & 2.9 \\
\hline & SMA & 13 & 37.1 & 37.1 & 37.1 \\
\hline & S1 & 20 & 57.1 & 57.1 & 100.0 \\
\hline & Total & 35 & 100.0 & 100.0 & \\
\hline
\end{tabular}

Sumber: Data Primer yang diolah, 2018 
Tabel 6: Golongan

\begin{tabular}{|c|c|c|c|c|c|}
\hline \multicolumn{2}{|l|}{} & Freq & Percent & $\begin{array}{c}\text { Valid } \\
\text { Percent }\end{array}$ & $\begin{array}{c}\text { Cumulative } \\
\text { Percent }\end{array}$ \\
\hline Valid & Gol I & 7 & 20.0 & 20.0 & 20.0 \\
\hline & Gol II & 5 & 14.3 & 14.3 & 34.3 \\
\hline & Gol III & 20 & 57.1 & 57.1 & 91.4 \\
\hline & Gol IV & 3 & 8.6 & 8.6 & 100.0 \\
\hline & Total & 35 & 100.0 & 100.0 & \\
\hline
\end{tabular}

Sumber: Data Primer yang diolah, 2018

Dari tabel diatas dapat diketahui bahwa responden terbanyak pada adalah laki-laki, dengan usia $<40$ tahun, pada tingkat pendidikan Dominan pada S1 dan golongan terbanyak yaitu Golongan III. Hal ini dapat di ketahui bahwa Responden pada kantor Sekretariat memenuhi usia produktif dan memiliki karakteristik dapat mengambil keputusan dengan benar.

\section{Uji Hipotesis}

Uji Hipotesis menggunakan teknik regresi linier berganda dengan melakukan beberapa Uji Asumsi klasik sebagai syarat sebelum melakukan uji hipotesis yakni sebagai berikut; Uji Multikolinearitas dan Uji Normalitas menggunakan SPSS dengan hasil sebagai berikut:

Tabel 7: Uji Multikolinearitas

\begin{tabular}{|c|c|c|c|c|c|c|}
\hline \multirow{2}{*}{\multicolumn{2}{|c|}{ Model }} & \multicolumn{2}{|c|}{$\begin{array}{c}\text { Unstandard } \\
\text { ized } \\
\text { Coefficient } \\
\text { s }\end{array}$} & \multirow{2}{*}{\begin{tabular}{|l}
$\begin{array}{c}\text { Standardi } \\
\text { zed } \\
\text { Coefficie } \\
\text { nts }\end{array}$ \\
\\
Beta
\end{tabular}} & \multicolumn{2}{|c|}{$\begin{array}{l}\text { Collinearity } \\
\text { Statistics }\end{array}$} \\
\hline & & B & $\begin{array}{c}\text { Std. } \\
\text { Erro } \\
r\end{array}$ & & $\begin{array}{c}\text { Tolera } \\
\text { nce }\end{array}$ & VIF \\
\hline 1 & $\begin{array}{l}\text { (Cons } \\
\operatorname{tant})\end{array}$ & $\begin{array}{l}5.8 \\
07\end{array}$ & $\begin{array}{c}2.27 \\
1\end{array}$ & & & \\
\hline & $\begin{array}{c}\text { finger } \\
\text { print }\end{array}$ & .191 & .180 & .182 & .589 & 1.699 \\
\hline
\end{tabular}

Berdasarkan tabel 7 nilai Tolerance dan VIF menunjukkan bahwa nilai Tolerance kedua variabel lebih dari 0,10 yaitu 0,589 yaitu $1,699 \%$, sehingga bisa diduga bahwa tidak ada masalah multikolinearitas antar variabel independen dalam model regresi.

Normal P-P Plot of Regression Standardized Residual

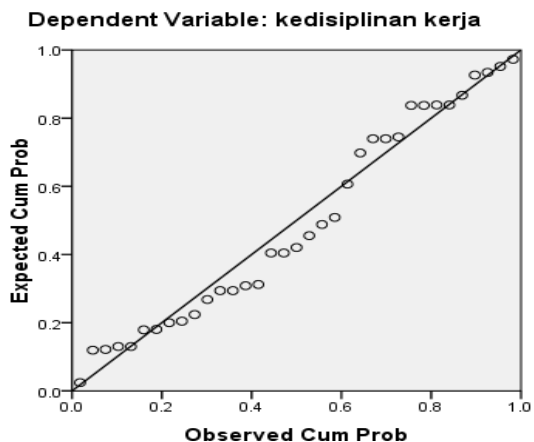

Gambar 1. Uji Normalitas

Berdasarkan pada gambar 1 grafik normal P-P Plot residual penyebaran data terletak di sekitar garis diagonal dan mengikuti arah garis diagonal, sehingga bisa diartikan bahwa distribusi data kedisiplinan karyawan adalah normal, sehingga bisa dilakukan regresi dengan model linier berganda.

\section{UJI REGRESI LINIER}

Dalam regresi linier, persamaan regresinya adalah $\mathrm{Y}=\alpha+\mathrm{b} . \mathrm{X}+\mathrm{e}$ yang digunakan untuk melakukan analisis secara simultan antara absensi sidik jari (finger print) (X) terhadap kedisiplinan karyawan (Y). Dengan menggunakan bantuan alat olah statistik SPSS Windows versi 16.0 diperoleh hasil perhitungannya sebagai berikut: 
Tabel 8: Hasil Analisis Regresi Linier

\section{Coefficients $^{\mathbf{a}}$}

\begin{tabular}{|c|c|c|c|c|c|c|}
\hline \multirow{2}{*}{\multicolumn{2}{|c|}{}} & \multicolumn{2}{c|}{$\begin{array}{c}\text { Unstandardized } \\
\text { Coefficients }\end{array}$} & \multicolumn{2}{c|}{$\begin{array}{c}\text { Standardized } \\
\text { Coefficients }\end{array}$} & \multicolumn{2}{c|}{ Collinearity Statistics } \\
\cline { 3 - 7 } & B & Std. Error & Beta & Tolerance & VIF \\
\hline 1 & (Constant) & 5.807 & 2.271 & & .589 & 1.699 \\
\hline & $\begin{array}{c}\text { finger } \\
\text { print }\end{array}$ & .191 & .180 & .182 & .589 \\
\hline
\end{tabular}

a.Dependent Variable: kedisiplinan kerja

Berdasarkan hasil analisis regresi pada tabel diatas diperoleh koefisien untuk variabel bebas $X=0,191$ dan konstanta sebesar 5,807 sehingga model persamaan regresi yang diperoleh adalah:

$$
Y=5,807+0,191 X+e
$$

Dimana :

$\mathrm{Y}=$ Variabel dependen (Kedisiplinan Pegawai)

$\mathrm{X}=$ Variabel independen (Absensi Sidik Jari)

a. Nilai konstan (Y) Sebesar 5,807 artinya jika variabel Absensi Sidik Jari (X) bernilai 0 (nol), maka Variabel Kedisiplinan Pegawai (Y) akan berada pada angka 5,807.

b. Koefisien regresi X (absensi sidik jari) dari perhitungan linier didapat nilai coefficients $(b)=0,191$. Hal ini berarti jika absensi sidik jari (X) dilaksanakan setiap hari secara disiplin maka volume kedisiplinan pegawai (Y) akan mengalami kenaikan sebesar 0,191\%. Dan karena koefiiennya bernilai positif maka terdapat hubungan yang positif antara absensi sidik jari dengan kedisiplinan pegawai.

\section{Uji Hipotesis Secasa Parsial}

Untuk menguji pengaruh variabel independen terhadap variabel dependen secara parsial, digunakan uji Statistik T (uji T). Apabila nilai $t$ hitung > nilai t tabel, maka $\mathrm{H} 0$ ditolak dan H1 diterima, sebaliknya apabila nilai $\mathrm{t}$ hitung <nilai $\mathrm{t}$ tabel, maka $\mathrm{H} 0$ diterima dan $\mathrm{H} 1$ ditolak. Hasil pengujian hipotesis secara parsial dapat dilihat pada Tabel 9. berikut ini:

Tabel 9. Uji Parsial (t)

\begin{tabular}{|c|c|c|c|c|c|c|}
\hline \multirow{2}{*}{ Model } & \multicolumn{2}{|c|}{ Unstandardized Coefficients } & Standardized Coefficients & \multirow{2}{*}{ S } & \multirow{2}{*}{ Sig. } \\
\cline { 3 - 7 } & B & Std. Error & Beta & & \\
\hline 1 & (Constant) & 5.807 & 2.271 & & 2.556 & .016 \\
\hline & finger print & .191 & .180 & .182 & 3.060 & .297 \\
\hline
\end{tabular}

Dependent Variable: kedisiplinan kerja

Dari tabel diatas dapat diketahui hasil dari variabel absensi sidik jari (finger print) (X) menunjukkan $\mathrm{t}$ hitung 3,060 dengan nilai signifikan sebesar 0,297 atau di atas 5\% $(0,05)$. Artinya pengaruh variabel absensi sidik jari (finger print) terhadap kedisiplinan pegawai adalah signifikan. Atau dengan kata lain $\mathrm{H} 1$ yang berbunyi "Pengaruh Efektivitas
Penerapan Absensi Finger Print Terhadap Disiplin Pegawai Negeri Sipil di Sekretariat Daerah Kabupaten Raja Ampat Papua Barat" adalah tidak dapat ditolak.

Analisis koefisien determinasi dilakukan untuk mengetahui seberapa besar nilai prosentase kontribusi variabel bebas terhadap variabel terikat. Dari hasil perhitungan melalui 
alat ukur statistik SPSS 16.0 for Windows didapatkan nilai koefisien determinasi sebagai berikut.

Tabel 10. Koefisien Determinasi $\left(\mathrm{R}^{2}\right)$

Model Summary ${ }^{\mathrm{b}}$

\begin{tabular}{|c|c|c|c|c|c|}
\hline Model & $\mathrm{R}$ & $\mathrm{R}$ Square & Adjusted R Square & $\begin{array}{c}\text { Std. Error of the } \\
\text { Estimate }\end{array}$ & Durbin- Watson \\
\hline 1 & $.668^{\mathrm{a}}$ & .446 & .411 & 1.47634 & 2.109 \\
\hline
\end{tabular}

a. Predictors: (Constant), finger print

b. Dependent Variable: kedisiplinan kerja

Tabel di atas menunjukkan bahwa 44,6\% variabel dependen (kedisiplinan karyawan) dapat dijelaskan oleh variabel independen (absensi sidik jari), sedangkan sisanya $55,4 \%$ dipengaruhi oleh variabel lain yang tidak diteliti dalam penelitian ini.

Hasil dari uji kofisien determinasi tersebut memberikan makna bahwa masih terdapat variabel independen lain yang mempengaruhi kedisiplinan karyawan. Untuk itu perlu pengembangan penelitian lebih lanjut terkait dengan topik ini.

PEMBAHASAN

Efektivitas Penerapan Absensi Fingerprint Terhadap Disiplin Kerja Pegawai

Fokus pada penelitian ini yakni Disiplin kerja pegawai dengan menunjukkan Efektifitas Penerapan Absensi Fingerprint yang merupakan system penghitungan kehadiran yang modern. Pemerintah Kabupaten Raja Ampat menerapkan absensi sidik jari (finger print) yang mulai berlaku dari tanggal 01 Desember 2010 sampai dengan sekarang. Selain itu, penerapan absensi sidik jari (finger print) ini dilakukan agar memudahkan atasan untuk melihat tingkat kedisiplinan dari masingmasing pegawai, karena selama ini absensi manual, atasan atau pegawai

lain yang melihat absensi tidak bisa melihat tingkat kedisiplinan pegawai, masalahnya pada absensi manual tidak ada keterangan kapan pegawai tersebut datang dan pulang, pegawai bisa merapel di hari lain atau menitip absen pada pegawai lain. Sehingga menyulitkan atasan untuk memberikan sanksi yang sesuai dengan Peraturan Pemerintah No. 53 tahun 2010 tentang Disiplin Pegawai Negeri Sipil.

Dari Hasil penelitian menunjukkan bahwa Penerapan Absensi Finger Print berpengaruh pada disiplin kerja pegawai, dari hasil tersebut dapat diartikan bahwa Absensi Finger Print Efektif untuk mengukur kedisiplinan pegawai Kantor Sekretariat Daerah Kabupaten Raja Ampat. Hasil penelitian tersebut sejalan dengan penelitian yang dilakukan oleh Maliah \& Saputra (2016), Zulfikar \& Kurniawati (2020), Agatha (2021), yang hasilnya mengatakan bahwa Disiplin Kerja di pengaruhi oleh penerapan Absensi Fingerprint adalah Efektif dan signifikan. Sedangkan Oktafiana et al., (2020) dan Fadila \& Septiana, (2019) mengatakan bahwa Absensi Fingerprint berpengaruh namun tidak signifikan terhadap Disiplin kerja. Pada Penelitian ini Hasil hipotesis pada uji t variabel absensi sidik jari (finger print) (X1) menunjukkan $\mathrm{t}$ 
hitung 3,060 dengan nilai 0,297 atau diatas 5\% (0,05). Sehigga pada akhirnya absensi sidik jari (finger print) mempunyai pengaruh signifikan terhadap kedisiplinan pegawai negeri sipil di sekretaris daerah Kabupaten Raja Ampat. Dengan demikian dapat disimpulkan bahwa berdasarkan pengujian terhadap 35 responden yang tercatat sebagai pegawai negeri sipil di sekretaris daerah Kabupaten Raja Amapat terbukti menerima Ha bahwa "terdapat pengaruh yang signifikan antara absensi sidik jari (finger print) dengan kedisiplinan pegawai", dan menolak H0 bahwa "tidak terdapat pengaruh yang signifikan antara absensi sidik jari (finger print) dengan kedisiplinan pegawai".

\section{PENUTUP}

\section{Simpulan}

Dari Hasil Penelitian dapat diketahui bahwa berdasarkan pengujian terhadap 35 responden yang tercatat sebagai pegawai negeri sipil di sekretaris daerah Kabupaten Raja Amapat terbukti menerima $\mathrm{Ha}$ bahwa "terdapat pengaruh yang signifikan antara absensi sidik jari (finger print) dengan kedisiplinan pegawai", dan menolak $\mathrm{H}_{0}$ bahwa "tidak terdapat pengaruh yang signifikan antara absensi sidik jari (finger print) dengan kedisiplinan pegawai".

\section{Saran}

Saran dalam penelitian ini adalah Untuk meningkatkan kedisiplinan pegawai, instansi selalu meninjau, memantau, dan memperbaiki sistem pelaksanaan sistem absensi sidik jari (finger print) yang sudah ada. Tujuannya untuk mengurangi sikap karyawan yang tidak begitu termotivasi dengan sistem absensi sidik jari (finger print) yang sudah ada. Hendaknya untuk mengembangkan penelitian ini dengan menggunakan variabel dan indikator yang berbeda sehingga dapat diperoleh informasi yang lebih lengkap tentang faktor-faktor yang mempengaruhi kedisiplinan pegawai negeri sipil.

\section{DAFTAR PUSTAKA}

Afandi, P. (2016). Concept \& Indicator Human Resources Management for Management Research.

Agatha, R. (2021). Pengaruh Efektifitas Absensi Fingerprint Terhadap Kedisiplinan Pegawai. X, 45-65.

Amalia, R., \& Adman. (2017). Pengaruh Insentif Terhadap Disiplin Kerja Pegawai Dinas Tenaga Kerja Kabupaten Bandung. 173-186.

Asmira. (2016). Efektivitas Penerapan Absensi (Fingerprint) Dalam Meningkatkan Disiplin Kerja Pegawai di Kecamatan Anggana Kabupaten Kutai Kartanegara. Ejournall Ilmu Pemerintahan, 4(3), 10091022.

Fadila, R., \& Septiana, M. (2019). Pengaruh Penerapan Sistem Absensi Finger Print Terhadap Disiplin Pegawai Pada Markas Komando Direktorat Pengamanan Badan Pengusahaan Batam. Journal of Applied Business Administration, 3(1), 53-63. https://doi.org/10.30871/jaba.v 3i1.1287 
Fathoni, A. (2014). Organisasi \& manajemen sumber daya manusia.

Maliah, \& Saputra, A. (2016). Pengaruh efektifitas absensi finger print terhadap disiplin pegawai pada dinas perindustrian dan perdagangan provinsi sumatera selatan. Jurnal Media Wahana Ekonomika, 13, 69-79.

Nugroho, E. (2009). Biometrika Mengenal Sistem Identifikasi Masa Depan.

Oktafiana, W., Riono, S. B., \& Syaifulloh, M. (2020). Pengaruh Efektivitas Penerapan Absensi Finger Print di Badan Pengelolaan Pendapatan Keuangan dan Aset Daerah (BPPKAD) Kabupaten Brebes. Journal Economics and Management(JECMA), 1(1), 23-32.

http://jurnal.umus.ac.id/index.p hp/jecma/article/view/222
Rahayu Rahmawati, S., \& Purwadhi. (2020). Pengaruh Efektivitas Penerapan Absensi Fingerprint dan Insentif Terhadap Disiplin Pegawai FPOK UPI. Jurnal Manajemen Jasa, 2(1), 31-41. http://ejurnal.ars.ac.id/index.ph $\mathrm{p} / \mathrm{jsj}$

Setiawan, D. R., \& Yulianti. (2018). Pengaruh Absensi Fingerprint Terhadap Disiplin Kerja Karyawan Pada Pt. Sanbio Laboratories Gunung Putri Kabupaten Bogor. Majalah Ilmiah Bijak, 14(1), 70-81. https://doi.org/10.31334/bijak.v $14 \mathrm{i} 1.61$

Zulfikar, D., \& Kurniawati, E. (2020). Pengaruh Efektivitas Absensi Finger Print Terhadap Disiplin Pegawai Pada Kantor Kesyahbandaran Dan Otoritas Pelabuhan (KSOP) Kelas IV Bima. Media Online ), 1(1), 1116. 